\title{
Molecular Dating in the Evolution of Vertebrate Poxviruses
}

\author{
Igor V. Babkin ${ }^{a}$ Irina N. Babkina ${ }^{b}$ \\ a Department of Molecular Immunology, Institute of Chemical Biology and Fundamental Medicine, Novosibirsk, \\ and ${ }^{b}$ Department of Poxviral Genomic Investigations, State Research Centre of Virology and Biotechnology \\ 'Vector', Koltsovo, Russia
}

\section{Key Words}

DNA virus $\cdot$ Poxviridae $\cdot$ Viral evolution $\cdot$ Bayesian relaxed clock

\begin{abstract}
Objectives: The goal of this work was to study the evolutionary history of the vertebrate poxviruses using the Bayesian relaxed clock and a large set of highly conserved vitally important viral genes. Methods: Phylogenetic analysis was performed by the maximum likelihood method using the Paup program. The dating method of Bayes, realized in the Multidivtime, was made. Results: The rate of poxviral evolution is estimated as $0.5-7 \times 10^{-6}$ nucleotide substitutions per site per year. We inferred that the modern viruses of the genus Avipoxvirus diverged from the ancestor nearly $249 \pm$ 69 thousand years ago (Tya). The progenitor of the genus Orthopoxvirus separated approximately $166 \pm 43$ Tya. The separation of the forebear of the genus Leporipoxvirus took place about $137 \pm 35$ Tya. The next to diverge was the ancestor of the genus Yatapoxvirus. The progenitor of Capripoxvirus and Suipoxvirus diverged $111 \pm 29$ Tya. Conclusion: The evolutionary analysis based on the historical data and utilizing the Bayesian relaxed clock allowed us to determine the molecular evolution rates of the AT-rich genomes of the vertebrate poxviruses and assess the times of their emergences. Involvement of a large set of the conserved genes controlled by stabilizing selection allowed us to perform molecular dating of the vertebrate poxvirus history.
\end{abstract}

Copyright $\odot 2011$ S. Karger AG, Basel
(C) 2011 S. Karger AG, Basel

0300-5526/11/0545-0253\$38.00/0

Fax +4161306 1234

E-Mail karger@karger.ch

www.karger.com
Accessible online at:

www.karger.com/int

\section{Introduction}

Members of the family Poxviridae are among the best studied cytoplasmic DNA viruses. According to the accepted taxonomy, they are divided into two subfamilies, Entomopoxvirinae and Chordopoxvirinae; the latter comprises eight genera and two unclassified viruses, deer poxvirus and crocodile poxvirus. There are two different types of evolutionary strategy in Chordopoxvirinae. Parapoxvirus, Molluscipoxvirus, and crocodile poxvirus accumulate GC sequences in their genomes, whereas the remaining viruses, AT sequences [1].

We earlier determined the molecular evolution rates of orthopoxvirus based on the analysis of the extended central conserved region in their genomes and of poxviruses with AT-rich genomes belonging to other genera based on the analysis of the nucleotide sequences of the genes encoding subunits of the viral RNA polymerase [2]. The rate of mutation accumulation in the genomes of these poxviruses was $1.7-4.8 \times 10^{-6}$ nucleotide substitutions per site per year. This value is higher by approximately 2 orders of magnitude as compared with the molecular evolutionary rate of their hosts. Nonetheless, this value is considerably lower than the corresponding rate in the genomes of RNA viruses. The divergence times for the main taxa in the subfamily Chordopoxvirinae were estimated as a result of this study [2]. The goal of the present work was to study the evolutionary history of the vertebrate poxviruses with AT-rich genomes applying the Bayesian relaxed clock method to a large set of highly 
Table 1. Genome sequences of the poxviruses

\begin{tabular}{|c|c|c|c|c|}
\hline Genus & Species & Strain & Abbreviation & GenBank \# \\
\hline \multirow[t]{10}{*}{ Orthopoxvirus } & Variola virus & $\begin{array}{l}\text { Brazil } 1966 \text { (v66-39 São Paulo) } \\
\text { Congo } 1970 \text { v70-46 Kinshasa } \\
\text { Garcia-1966 } \\
\text { Guinea } 1969 \text { (005) } \\
\text { India } 19647124 \text { Vellore } \\
\text { Sierra Leone } 1969 \text { (V68-258) }\end{array}$ & $\begin{array}{l}\text { VARV BRZ66 } \\
\text { VARV CNG70 } \\
\text { VARV GAR } \\
\text { VARV GUI69 } \\
\text { VARV IND64 } \\
\text { VARV SLN68 }\end{array}$ & $\begin{array}{l}\text { DQ441419 } \\
\text { DQ437583 } \\
\text { Y16780 } \\
\text { DQ441426 } \\
\text { DQ437585 } \\
\text { DQ441437 }\end{array}$ \\
\hline & Camelpox virus & M-96 & CMLV M96 & AF438165 \\
\hline & Taterapox virus & Dahomey 1968 & TATV & NC_008291 \\
\hline & \multirow{3}{*}{ Cowpox virus } & GRI-90 & CPXV GRI & X94355 \\
\hline & & Brighton Red & CPXV BRI & AF482758 \\
\hline & & Germany 91-3 & CPXV GER & DQ437593 \\
\hline & Ectromelia virus & Moscow & ECTV MOS & AF012825 \\
\hline & Horsepox virus & MNR-76 & HPXV & DQ792504 \\
\hline & \multirow{2}{*}{ Monkeypox virus } & Zaire-96-I-16 & MPXV Z96 & AF380138 \\
\hline & & Sierra Leone V70 & MPXV SL & AY741551 \\
\hline Yatapoxvirus & Yaba monkey tumor virus & YLD & YMTV YLD & AJ293568 \\
\hline \multirow[t]{3}{*}{ Capripoxvirus } & Lumpy skin disease virus & Neethling 2490 & LSDV 2490 & AF325528 \\
\hline & Sheeppox virus & & SPPV A & AY077833 \\
\hline & Goatpox virus & G20-LKV & GTPV G20 & AY077836 \\
\hline Suipoxvirus & Swinepox virus & $17077-99$ & SWPV 99 & AF410153 \\
\hline Leporipoxvirus & Myxoma virus & Lausanne & MYXV LAU & AF170726 \\
\hline \multirow[t]{2}{*}{ Avipoxvirus } & Fowlpox virus & FCV & FWPV FCV & AF198100 \\
\hline & Canarypox virus & Wheatley C93 & CNPV WC93 & NC_005309 \\
\hline Molluscipoxvirus & Molluscum contagiosum virus & Subtype 1 & MOCV SB1 & MCU60315 \\
\hline Unclassified & Deerpox virus & W-848-83 & DPXV W83 & AY689436 \\
\hline
\end{tabular}

conserved vitally important viral genes. This approach is based on a probabilistic model of the changes in evolutionary rates and utilizes the Markov chain Monte Carlo (MCMC). This provides for estimation of an a posteriori distribution of the evolutionary rates and divergence time estimates. An expanded set of data on the gene nucleotide sequences made it possible to perform the evolutionary analysis with a higher reliability.

\section{Materials and Methods}

Sequence Retrieval

Nucleotide sequences of vertebrate poxviruses were extracted from the NCBI database. Table 1 lists the poxviruses used in this work.

\section{Aligning of Nucleotide Sequences}

When analyzing the genome primary structures of 25 strains belonging to different vertebrate poxvirus genera (table 1), we used the sequences of 35 highly conserved genes (table 2). These sequences were aligned using the CLUSTAL_X version 1.8 program [3] into 35 individual nucleotide alignments and then concatenated into one extended alignment.

\section{Phylogenetic Analysis}

This study was performed by the maximum likelihood (ML) method using the program Paup 4.0b10 (version 4; Sinauer Associates, Sunderland, Mass., USA). The model of evolution was preliminarily determined with the help of a likelihood ratio (LR) test [4] using the Modeltest version 3.7 program [5]. Permutation analysis of statistical significance of the constructed tree was conducted using 100 replicates and the same strategy and parameters. The trees were visualized with the Mega version 3.1 program [6].

Statistical Tests

Constancy of the evolutionary rates was tested by means of LR test [4] for all the trees obtained in this work.

\section{Molecular Dating}

The dating method of Bayes, realized in the Multidivtime version 1.5 program [7], was used in this work. At the first stage, the Baseml program from the software package Paml (3.0 ed.; Uni- 
Table 2. The highly conserved genes for the family Poxviridae

\begin{tabular}{|c|c|c|}
\hline ORF & $\begin{array}{l}\text { Protein length } \\
\text { aa }\end{array}$ & Function \\
\hline F10L & 439 & $\begin{array}{l}\text { Serine/threonine protein kinase } 2 \text { VPK2, membrane-associated phosphoprotein involved in } \\
\text { virion morphogenesis }\end{array}$ \\
\hline$\overline{\mathrm{E} 1 \mathrm{~L}}$ & 479 & Poly(A) polymerase catalytic subunit \\
\hline$\overline{\mathrm{E} 4 \mathrm{~L}}$ & 259 & RNA polymerase $30-\mathrm{kDa}$ subunit, intermediate transcription factor VITF-1 \\
\hline$\overline{\mathrm{E} 9 \mathrm{~L}}$ & 1,006 & DNA polymerase \\
\hline E10R & 95 & Sulfhydryl oxidase, disulfide bond formation pathway protein \\
\hline I8R & 676 & Nucleoside triphosphate phosphohydrolase II, NTP-dependent DNA and RNA helicase \\
\hline$\overline{\mathrm{G} 2 \mathrm{R}}$ & 220 & Late positive transcription elongation factor \\
\hline$\overline{\mathrm{G} 4 \mathrm{~L}}$ & 124 & $\begin{array}{l}\text { Glutaredoxin, intermediate of a cytoplasmic disulfide bond pathway required for virion } \\
\text { assembly }\end{array}$ \\
\hline$\overline{\mathrm{G} 5.5 \mathrm{R}}$ & 63 & RNA polymerase $7-\mathrm{kDa}$ subunit \\
\hline$\overline{\mathrm{G} 8 \mathrm{R}}$ & 260 & Late transcription factors VLTF-1 \\
\hline $\mathrm{J} 3 \mathrm{R}$ & 333 & $\begin{array}{l}\text { Poly(A) polymerase small subunit, cap-specific mRNA (nucleoside-2'-O-)-methyltransferase, } \\
\text { positive transcription elongation factor }\end{array}$ \\
\hline $\mathrm{J} 4 \mathrm{R}$ & 185 & RNA polymerase $22-\mathrm{kDa}$ subunit \\
\hline$\overline{\mathrm{J} 6 \mathrm{R}}$ & 1,286 & RNA polymerase $147-\mathrm{kDa}$ subunit \\
\hline H1L & 171 & Serine/tyrosine/threonine protein phosphatase \\
\hline H4L & 795 & RNA polymerase-associated transcription specificity factor Rap94 \\
\hline$\overline{\mathrm{H} 5 \mathrm{R}}$ & 203 & $\begin{array}{l}\text { Late transcription factor VLTF-4, multifunctional protein involved in viral DNA replication, } \\
\text { postreplicative gene transcription and virion morphogenesis }\end{array}$ \\
\hline H6R & 314 & DNA topoisomerase type I \\
\hline$\overline{\mathrm{D} 1 \mathrm{R}}$ & 844 & $\begin{array}{l}\text { mRNA capping enzyme large subunit, mRNA guanyltransferase, early and intermediate gene } \\
\text { transcription termination factor }\end{array}$ \\
\hline$\overline{\mathrm{D} 4 \mathrm{R}}$ & 218 & $\begin{array}{l}\text { Uracil DNA glycosylase, protein necessary for assembly of a processive polymerase } \\
\text { holoenzyme and essential for DNA replication }\end{array}$ \\
\hline D5R & 785 & NTPase, protein essential for DNA replication \\
\hline$\overline{\mathrm{D} 6 \mathrm{R}}$ & 637 & $\begin{array}{l}\text { Early transcription factor small subunit VETF, DNA binding protein, ATP-dependent } \\
\text { helicase }\end{array}$ \\
\hline$\overline{\mathrm{D} 7 \mathrm{R}}$ & 161 & RNA polymerase $18-\mathrm{kDa}$ subunit \\
\hline$\overline{\mathrm{D} 11 \mathrm{~L}}$ & 631 & $\begin{array}{l}\text { Nucleoside triphosphate phosphohydrolase I (NPH I), DNA-dependent ATPase, early gene } \\
\text { transcription termination factor }\end{array}$ \\
\hline$\overline{\mathrm{D} 12 \mathrm{~L}}$ & 287 & $\begin{array}{l}\text { mRNA capping enzyme small subunit, mRNA (guanine-N7)-methyltransferase, early and } \\
\text { intermediate gene transcription termination factor }\end{array}$ \\
\hline A1L & 150 & Late transcription initiation factor VLTF-2 \\
\hline $\mathrm{A} 2 \mathrm{~L}$ & 224 & Late transcription factor VLTF-3 \\
\hline$\overline{\mathrm{A} 2.5 \mathrm{~L}}$ & 76 & Thiol oxidoreductase, protein involved in disulfide bond formation pathway \\
\hline A5R & 164 & RNA polymerase $19-\mathrm{kDa}$ subunit \\
\hline$\overline{\mathrm{A} 7 \mathrm{~L}}$ & 710 & $\begin{array}{l}\text { Early transcription factor large subunit VETF, protein necessary for morphogenesis of the } \\
\text { virion core }\end{array}$ \\
\hline A8R & 288 & Intermediate transcription factor (VITF-3) 34-kDa subunit \\
\hline A18R & 493 & DNA helicase, post-replicative negative transcription elongation factor \\
\hline A20R & 426 & DNA polymerase processivity factor VPF \\
\hline A23R & 382 & Intermediate transcription factor (VITF-3) 45-kDa subunit \\
\hline A24R & 1,164 & RNA polymerase $132-\mathrm{kDa}$ subunit \\
\hline$\overline{\mathrm{A} 29 \mathrm{~L}}$ & 305 & RNA polymerase $35-\mathrm{kDa}$ subunit \\
\hline
\end{tabular}

versity College London, UK) was used to calculate the ML parameters of evolution model F84 + G using the predetermined ML topology. The divergence time was calculated using the Multidivtime program in two steps. First, the Estbranches program determined the lengths of the tree branches with the help of the F84 evolution model together with the divergence covariance matrix. Then the external group of trees was removed by Multidivtime and the MCMC analysis was conducted. This analysis estimates the mean posterior times of node divergence connected with the standard deviations from the covariance matrix constructed by Estbranches. During this work, we performed two independent MCMC analyses with different starting points to confirm the reproducibility of results. 


\section{Results}

\section{Phylogenetic Relationships}

The genes of poxviruses are classified into speciesand genus-specific genes and the genes conserved for the family Poxviridae [8]. Overall, 90 conserved genes are present in the genomes of all chordopoxviruses and, presumably, they were also present in their common ancestor $[1,8,9]$. The majority of the proteins encoded by these genes are involved in transcription, mRNA biosynthesis, DNA repair and replication, protein modification, or are structural components of virions. Except for rare exceptions, the gene synteny in vertebrate poxviruses is highly conserved $[9,10]$.

To elevate the reliability of phylogenetic analysis, it is reasonable to use a concatenated alignment of a large number of gene loci. This approach gives more reliable results because of an increased number of phylogenetically informative sites [11]. However, the involvement of genes with different rates of accumulation of nucleotide substitutions can bring about a potential problem of obtaining artifacts $[12,13]$. Therefore, we selected only highly conserved genes with similar evolutionary rates. Lefkowitz et al. [9] selected 35 genes meeting these criteria. These genes encode the proteins E1L, E4L, I8R, G2R, G5.5R, G8R, J3R, J4R, J6R, H4L, H5R, H6R, D1R, D4R, D5R, D6R, D7R, D11L, D12L, A1L, A2L, A5R, A7L, A8R, A18R, A23R, A24R, and A29L, involved in DNA transcription [14-16]; F10L, E9L, H1L, and A20R, involved in DNA replication [16-18], and E10R, G4L, and A2.5L, involved in the formation of S-S bonds [16, 19] (table 2).

In this work, we constructed 35 alignments of the above listed genes for six AT-rich vertebrate poxvirus genera and one unclassified virus, deer poxvirus, as well as one representative of the GC-rich genera, molluscum contagiosum virus (table 1), chosen as an outgroup. We studied 15 representatives of the genus Orthopoxvirus, including six strains of variola virus (VARV), because it allowed us to date the maximal time of divergence between the West African and South American VARV variants in the further evolutionary study. The vaccinia virus strains (except HPXV) have a long history of passages under laboratory conditions, which might distort the picture of their evolutionary relationships with natural poxvirus isolates. Hence, these strains were excluded from analysis. For the genus Avipoxvirus, we took the canarypox virus and fowlpox virus, displaying considerable nucleotide heterogeneity. Then the individual alignments for each of the 35 genes were concatenated into one extended alignment with a length of $48,178 \mathrm{bp}$. The resulting data were used in phylogenetic analysis. At the first stage, we selected a general time-reversible process GTR + G + I model of sequence evolution and its parameters using the Model Test program $(\mathrm{R}$ matrix $=(2.2972,4.7313,1.2526$, $0.7300,7.9071)$; base frequencies $=(0.3480,0.1873,0.1938$, $0.2709)$; ratio of invariant sites $=0.2273$, and shape parameter of $\gamma$-distribution of variable site rates $=0.9216$ ). Applying this model with molecular clock option, we constructed the phylogeny of vertebrate poxviruses, an ML tree. The constructed phylogeny with a high degree of reliability determines the topology of taxa within the subfamily Chordopoxvirinae and agrees with the published data $[2,9,20,21]$.

\section{Estimation of Divergence Times}

An applicability of the hypothesis of strict molecular clock to the performed evolutionary analysis of poxviruses was verified using the LR test. It has been found that this hypothesis is inapplicable due to the differences in the rates of mutation accumulation between different branches in phylogeny. Correspondingly, we have applied an alternative method of the Bayesian relaxed clock, which take into account the difference in the evolutionary rates [7]. In this analysis, we have used the previously derived topology of ML tree, discarding the data for molluscum contagiosum virus from the calculation. A high level of mutations in the genome of this GC-rich virus interferes with an adequate dating of its divergence from the remaining studied species. Use of molluscum contagiosum virus was necessary to determine the position of the tree root constructed by Bayesian analysis. The following priors, assessed in the Estbranches program, were used in the Multidivtime program: $\mathrm{rttm}=4.8(\mathrm{rttmsd}=$ $4.8)$ and rtrate $=0.16($ rtratesd $=0.16)$. The following time constraints have been used: the time of divergence of South American VARV strains from West African strains must not exceed 400 years $[2,22]$ and the time of VARV emergence must fall between 1.9 and 10 Tya. The first constraint stems from the reliable information about the absence of smallpox and the corresponding pathogen on the American continent before its discovery by Europeans in the 16th century. The smallpox epidemics commenced in South America after the slaves from West Africa were brought there [23]. The second constraint is connected with the fact that an epidemic disease, such as smallpox, requires a high concentration of sensitive hosts. Such a situation could arise only after development of land farming and large settlements, which took place between 5 and 10 Tya [23-25]. On the other hand, the most ancient description of this disease, dated back to the 4 th 
Table 3. Divergence times for poxviruses and mutation accumulation rates in the main nodes of the evolutionary tree of vertebrate poxviruses with AT-rich genomes shown in figure 1

\begin{tabular}{lll}
\hline Node & $\begin{array}{l}\text { Divergence time and } \\
\text { standard deviation } \\
\text { (thousand years) }\end{array}$ & $\begin{array}{l}\text { Mutation accumulation rate and } \\
\text { standard deviation (nucleotide } \\
\text { substitutions per site per year } \times 10^{-6} \text { ) }\end{array}$ \\
\hline 1 & $249 \pm 69$ & $6.8 \pm 2.2$ \\
2 & $166 \pm 43$ & $6.8 \pm 2.2$ \\
3 & $137 \pm 35$ & $6.4 \pm 1.8$ \\
4 & $121 \pm 31$ & $5.6 \pm 1.6$ \\
5 & $111 \pm 29$ & $5.3 \pm 1.5$ \\
6 & $35 \pm 8$ & $0.5 \pm 0.2$ \\
7 & $21 \pm 3$ & $0.5 \pm 0.1$ \\
8 & $18 \pm 3$ & $0.4 \pm 0.1$ \\
9 & $8.6 \pm 1.0$ & $0.5 \pm 0.1$ \\
10 & $2.6 \pm 0.6$ & $0.7 \pm 0.1$ \\
\hline
\end{tabular}

century AD, tells that smallpox was recorded in China between the years 25 and $40 \mathrm{AD}$ [23], i.e. over 1.9 Tya.

Application of the Bayesian method in evolutionary reconstruction allowed us to determine the time when different genera in the subfamily Chordopoxvirinae were formed as well as the rate of mutation accumulation in the nodes of the chronogram (fig. 1; table 3 ).

\section{Discussion}

Currently, the issue of molecular dating in the evolutionary history of the viruses with extended DNA genomes remains unclarified due to a low rate of mutation accumulation in these genomes. On the other hand, the evolutionary time scale of the animals that are natural hosts of these viruses is mainly based on paleontological data.

In the modern systematics, the generally accepted approach is a comparative study of the homologous nucleotide sequences of conserved genes or amino acid sequences of the proteins they encode. Such an approach makes it possible to determine the number of substitutions per site appearing in the studied sequences during their evolution from the common ancestor. When there is additional historical evidence about the time of divergence of a taxon, it is possible to calculate the molecular evolution rate and date the origin of all taxa assuming a constancy of the mutation accumulation rate (molecular clock hypothesis) [26]. However, in the majority of cases, testing

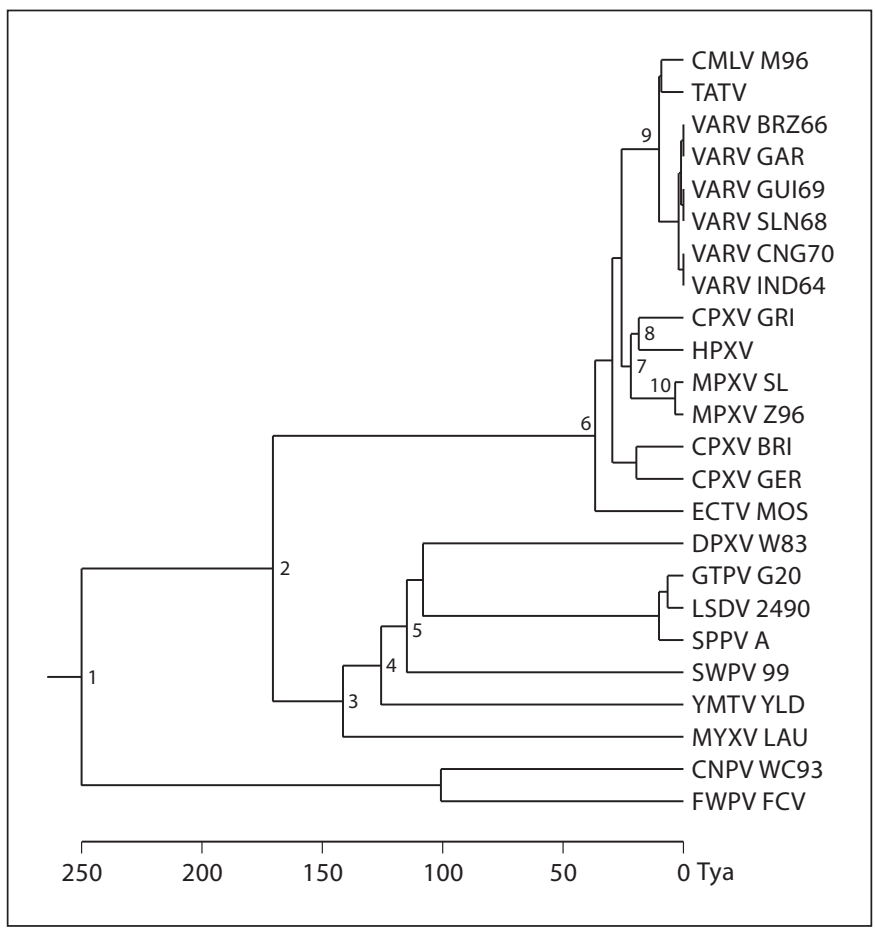

Fig. 1. Chronogram: the divergence times for vertebrate poxviruses with AT-rich genomes estimated using the Multidivtime program based on the analysis of nucleotide sequences of 35 highly conserved genes. The designations are listed in table 1 ; the values of divergence times and rates of accumulation of nucleotide substitutions for main tree nodes $1-6$ are given in table 2 .

of this hypothesis demonstrates inappropriateness of this approach. So far, the methods of evolutionary dating that take into account an inconstant evolutionary rate have been developed. The method of Bayesian relaxed clock has become the most generally accepted [27].

To introduce the time scale into the evolutionary reconstruction, it is necessary to determine the divergence times in one or several nodes of the tree. We have earlier discovered the genetic relation between the virus strains from West Africa and South America, which form a separate VARV biological subtype [22]. Phylogenetic analysis of this subtype demonstrates that the mentioned strains form separate groups according to geographic characteristics, thereby confirming their independent evolution from the common ancestor for a certain time period. This agrees with historical data about the export of VARV to South America in the 16th century with the slaves from West Africa, which caused devastating epidemics among the aboriginal population [23]. It is known that during colonization of Americas, VARV strains were 
repeatedly imported to these continents. However, only the VARV biological variant from West Africa was the ancestor of the endemic variola minor alastrim in South America. Variola minor alastrim causes the disease with a mortality rate of below $1 \%$, while the VARV strains from West Africa, of $8-12 \%$. These data suggest that the divergent evolution of these geographically separated VARV variants commenced not earlier than the 16th century (no more than 400 years until the moment the strains were isolated). According to our opinion, this dating is the most reliable for studying the molecular evolution of poxviruses. To increase the reliability of analysis, we also used an additional time constraint for VARV emergence -1.9 to 10 Tya, as described above.

The earlier calculation using the Bayesian relaxed clock based on the genes encoding RNA polymerase subunits has demonstrated that the divergence of the mammalian poxvirus genera with the DNA displaying low GC content took place approximately 110-90 Tya and the progenitor of the genus Orthopoxvirus separated $131 \pm$ 45 Tya. The calculated time of divergent evolution of West African orthopoxvirus subtypes based on the analysis of extended conserved genomic region was estimated approximately as $600 \pm 80$ years ago for VARV and 2.6 \pm 0.9 Tya for monkeypox virus. In both cases, the rate of mutation accumulation in the genomes of the studied vertebrate poxviruses was $1.7-8.8 \times 10^{-6}$ nucleotide substitutions per site per year [2].

For evolutionary studies, it is reasonable to accurately select the genomic loci to be analyzed. Use of highly conserved genes controlled by stabilizing selection provides for a high reliability of such analysis. Within poxvirus population, it is also necessary to select the genomic loci with a low probability of recombination events that would not interfere with a correct phylogenetic reconstruction. We earlier performed an evolutionary analysis involving eight genes coding for individual vertebrate poxvirus RNA polymerase subunits and the extended genus-specific central conserved region in orthopoxvirus genomes [2]. In this work, we have studied 35 conserved genes of AT-rich viruses common for all genera of the subfamily Chordopoxvirinae. The topology of the constructed trees match well both one another and the phylogenetic data obtained by analysis of the amino acid sequences deduced for these 35 genes [9].

In this work, the rate of accumulation of nucleotide substitutions is estimated as $0.5-7 \times 10^{-6}$ nucleotide substitutions per site per year. Applying the Bayesian method for time estimates (fig. 1; table 2), we inferred that the modern viruses of the genus Avipoxvirus diverged from the ancestor approximately $249 \pm 69$ Tya. Analysis of the chronogram suggests that the forebear virus of the modern mammalian poxviruses had a wide host range. During the evolution, this forefather virus had specialized to different host organisms. The progenitor of the genus Orthopoxvirus was the first to diverge approximately $166 \pm$ 43 Tya. It was followed by separation of the ancestor of the genus Leporipoxvirus, which took place about $137 \pm$ 35 Tya. This genus comprises the viruses causing tumorigenesis in rabbits, hares, and squirrels. The next to diverge was the progenitor of the genus Yatapoxvirus; members of this genus induce benign tumors in primates. The forebear of three virus genera - Capripoxvirus, Suipoxvi$r u s$, and deerpox virus, recently discovered and yet unclassified - diverged $111 \pm 29$ Tya.

The forefather of the ectromelia virus was the first to diverge about $35 \pm 8$ Tya in orthopoxviral cluster (fig. 1; table 2), the ancestor of the monkeypox virus separated from CPXV GRI and horsepox virus progenitor approximately $21 \pm 3$ Tya. VARV separated from the ancestor common for camelpox virus and taterapox virus $8.6 \pm$ 1.0 Tya. On the other hand, our earlier calculation based on the extended central conserved region of orthopoxvirus genomes, which comprises 102 genes, allowed us to estimate the time of independent VARV evolution as 3.4 \pm 0.8 Tya [2]. This dating of the origin of VARV ancestor at about 3-4 Tya demonstrates that VARV is a relatively young virus; this explains the absence of smallpox epidemics in the ancient historical records (Talmud, Bible, and others). However, analogous comparative analysis of extended genomic regions is impossible for the representatives of various vertebrate poxviruses because of considerable intergeneric differences in their organization [10]. As for orthopoxviruses, the data obtained based on the extended conserved genomic region are more reliable [2].

Li et al. [28] estimated the time of VARV emergence and its spreading over the globe. The authors used condensed alignment of orthopoxviral nucleotide sequences and analyzed only the SNPs that met the requirement of seven nucleotides surrounding and conserved on both sides of the SNP. The complete orthopoxvirus genomes were studied in evolutionary analysis in this paper. However, the virulence genes cluster to the terminal variable regions of genomes [16]. Many of these genes are under the control of adaptive selection and are therefore inappropriate for analyzing the evolutionary rate [29]. In addition, recombinational rearrangements were revealed only in the terminal regions of the orthopoxviral genomes $[1,30]$. 
Two different assumptions on the time of emergence of VARV were proposed by Li et al. [28]. The first analysis was based on the prior that VARV was imported to the south of Africa in 1713 and then colonized the overall continent. However, there are numerous documentary records for earlier smallpox spread on this continent; as for North Africa, VARV was present there at least as early as the 7th century AD [23]. The second assumption is based on the ancient Chinese manuscript and the prior that VARV existed over 1.6 Tya. Consequently, the authors inferred that VARV emerged in the first case 16 Tya and in the second, 68 Tya using a strict molecular clock and that smallpox appeared on the American continent long before Columbus discovered America. This contradicts the historical records that the American population over 10 years of its colonization was reduced by almost 9 million people, mainly due to smallpox [23].

The evolutionary analysis based on the historical data and utilizing the Bayesian relaxed clock allowed us to specify its characteristics relative to a wide range of the vertebrate poxviruses with AT-rich genomes. Three time constraints were used in this analysis. It has been found that the main vertebrate poxvirus genera diverged 100 300 Tya. The rate of mutation accumulation in the genomes of these viruses is about $10^{-6}$ nucleotide substitu- tions per site per year. These results agree with data for orthopoxviruses estimated both on the basis of central conservative region [2] and in study of rates of synonymous mutation accumulation in the genome of these viruses [21]. The molecular evolution rates obtained for vertebrate poxviruses are 2 orders of magnitude lower than those of viruses with single-stranded DNA genomes, 2-3 orders of magnitude lower than those of viruses with single-stranded RNA genomes [31], and 3-4 orders of magnitude higher that those of animal chromosomal genes [32].

Involvement of a large set of the conserved genes controlled by stabilizing selection allowed us to perform molecular dating of the vertebrate poxvirus history with high reliability. Comparability of estimates and reproducibility of the topology with the models that we earlier constructed $[2,21]$ in the evolutionary analysis of vertebrate poxviruses confirm the adequateness of this approach.

\section{Acknowledgement}

This work was supported by the Russian Foundation for Basic Research (project No. 08-04-00443-a).

\section{References}

$>1$ Gubser C, Hue S, Kellam P, Smith GL: Poxvirus genomes: a phylogenetic analysis. J Gen Virol 2004;85:105-117.

-2 Babkin IV, Shchelkunov SN: Molecular evolution of poxviruses. Genetika 2008;44 1029-1044.

-3 Thompson JD, Gibson TJ, Plewniak F, Jeanmougin F, Higgins DG: The CLUSTAL_X Windows interface: flexible strategies for multiple sequence alignment aided by quality analysis tools. Nucleic Acids Res 1997;25: 4876-4882.

4 Huelsenbeck JP, Rannala B: Maximum likelihood estimation of phylogeny using stratigraphic data. Paleobiology 1997;23:174-180.

$\checkmark 5$ Posada D, Crandall KA: Modeltest: testing the model of DNA substitution. Bioinformatics 1998;14:817-818.

6 Kumar S, Tamura K, Nei M: MEGA3: integrated software for molecular evolutionary genetics analysis and sequence alignment. Brief Bioinform 2004;5:150-163.

7 Kishino H, Thorne JL, Bruno WJ: Performance of a divergence time estimation method under a probabilistic model of rate evolution. Mol Biol Evol 2001;18:352-361.
$>8$ Upton C, Slack S, Hunter AL, Ehlers A, Roper RL: Poxvirus orthologous clusters: toward defining the minimum essential poxvirus genome. J Virol 2003;77:7590-7600.

$>9$ Lefkowitz EJ, Wang C, Upton C: Poxviruses: past, present and future. Virus Res 2006;117: 105-118.

10 McLysaght A, Baldi PF, Gaut BS: Extensive gene gain associated with adaptive evolution of poxviruses. Proc Natl Acad Sci USA 2003; 100:15655-15660.

11 Brown JR, Douady CJ, Italia MJ, Marshall WE, Stanhope M J: Universal trees based on large combined protein sequence data sets. Nat Genet 2001;28:281-285.

12 Anderson FE, Swofford DL: Should we be worried about long-branch attraction in real data sets? Investigations using metazoan $18 \mathrm{~S}$ rDNA. Mol Phylogenet Evol 2004;33:440451.

13 Shackelton LA, Holmes EC: The evolution of large DNA viruses: combining genomic information of viruses and their hosts. Trends Microbiol 2004;12:458-465.
14 Condit RC, Niles EG: Regulation of viral transcription elongation and termination during vaccinia virus infection. Biochim Biophys Acta 2002;1577:325-336.

15 Broyles SS: Vaccinia virus transcription. J Gen Virol 2003;84:2293-2303.

16 Shchelkunov SN, Marennikova SS, Moyer RW: Orthopoxviruses Pathogenic for $\mathrm{Hu}$ mans. Berlin, Springer, 2005.

17 Traktman P: Poxvirus DNA replication; in Depamphilis ML (ed): DNA Replication in Eukaryotic Cells. Cold Spring Harbor, Cold Spring Harbor Laboratory, 1996, pp 775 798.

18 Moss B: Poxviridae: the viruses and their replication; in Knipe DM, Howley PM (eds): Fields Virology. Philadelphia, LippincottRaven, 2001, pp 2849-2884.

19 Senkevich TG, White CL, Koonin EV, Moss B: Complete pathway for protein disulfide bond formation encoded by poxviruses. Proc Natl Acad Sci USA 2002;99:6667-6672.

20 Babkin IV, Shchelkunov SN: The time scale in poxvirus evolution. Mol Biol (Mosk) 2006; 40:20-24. 
21 Hughes AL, Irausquina S, Friedman R: The evolutionary biology of poxviruses. Infect Genet Evol 2010;10:50-59.

22 Babkina IN, Babkin IV, Li Y, Ropp S, Kline R, Damon IK, Esposito JJ, Sandakhchiev LS, Shchelkunov SN: Phylogenetic comparison of the genomes of different strains of variola virus. Dokl Biochem Biophys 2004;398:316319.

23 Fenner F, Henderson DA, Arita I, Jezek Z, Ladnyi ID: Smallpox and Its Eradication. Geneva, WHO, 1988.

24 Gubser C, Smith GL: The sequence of camelpox virus shows it is most closely related to variola virus, the cause of smallpox. J Gen Virol 2002;83:855-872.
25 Institute of Medicine (USA): Committee on the Assessment of Future Scientific Needs for Live Variola Virus: Assessment of Future Scientific Needs for Live Variola Virus. Washington, National Academies Press, 1999.

26 Margoliash E: Primary structure and evolution of cytochrome C. Proc Natl Acad Sci USA 1965;50:672-679.

7 Drummond AJ, Ho SY, Phillips MJ, Rambaut A: Relaxed phylogenetics and dating with confidence. PLoS Biol 2006;4:e88.

28 Li Y, Carroll DS, Gardner SN, Walsh MC, Vitalis EA, Damon IK: On the origin of smallpox: correlating variola phylogenics with historical smallpox records. Proc Natl Acad Sci USA 2007;104:15787-15792.
29 Chang BSW, Donoghue MJ: Recreating ancestral proteins. Trends Ecol Evol 2000;15: 109-114.

30 Esposito JJ, Sammons SA, Frace AM, Osborne JD, Glsen-Rasmussen M, Zhang M, Govil D, Damon IK, Kline R, et al: Genome sequence diversity and clues to the evolution of variola (smallpox) virus. Science 2006;313: 807-812.

31 Jenkins GM, Rambaut A, Pybus OG, Holmes EC: Rates of molecular evolution in RNA viruses: a quantitative phylogenetic analysis. J Mol Evol 2002;54:156-165.

32 Kumar S, Hedges SB: A molecular timescale for vertebrate evolution. Nature 1998;392. 917-920. 